\title{
¿SIGUEN VIGENTES LOS MODELOS TEÓRICOS CLÁSICOS DE LA INSERCIÓN LABORAL JUVENIL?
}

\section{ARE THE CLASSIC THEORETICAL MODELS OF YOUTH LABOR INSERTION STILL VALID?}

\author{
José Manuel García-Moreno \\ Universidad de Granada \\ josemgar@ugr.es
}

\author{
Laura Feliciano-Pérez \\ Universidad Internacional de la Rioja \\ laura.feliciano@unir.net
}

\section{Resumen}

La vigencia de cualquier teoría depende de que sus hipótesis resistan al paso del tiempo y a la evidencia empírica más allá de la época en que fueron planteadas. En este trabajo se realiza el esfuerzo de contrastar las teorías clásicas de la inserción laboral, tratando de validarlas nuevamente, pero con datos más recientes, para el contexto español y centrando la atención en la población joven de nuestro país entre 2006 y 2014 (todo el periodo que va desde los albores de la crisis económica -antes de 2007- hasta 2014, momento donde la economía española parecía mejorar). Con datos de diferentes fuentes (teóricas y estadísticas) se ha tratado de confirmar la actualidad o no de dichos planteamientos teóricos clásicos concluyendo que, con matices propios del contexto temporal elegido, muchas de las hipótesis de esas teorías siguen siendo útiles aún para el análisis, interpretación y explicación de la inserción laboral de los jóvenes en España.

Palabras Clave: Juventud, empleo, mercado de trabajo, formación, movilidad social, estatus, España.

\section{Abstract}

The validity of any theory depends on its hypothesis resisting the passage of time and empirical evidence beyond the time they were raised. In this paper an effort is made to contrast the classical theories of labor insertion, trying to validate them again, but with more recent data, for the Spanish context and focusing attention on the young population of our country between 2006 and 2014 (the entire period that goes from the dawn of the economic crisis - before 2007 - until 2014, when the Spanish economy seemed to improve). With data from different sources (theoretical and statistical) we have tried to confirm or not the current approach of such classical theoretical approaches, concluding that, with nuances of the chosen temporal context, many of the hypotheses of these theories are still useful for the analysis, the interpretation and explanation of the labor insertion of young people in Spain.

Keywords: Youth, employment, labor market, training, social mobility, status, Spain.

Este trabajo forma parte de los resultados obtenidos bajo el marco del proyecto de investigación Nuevas estructuras de sociabilidad: redes sociales presenciales y digitales (Ref. CSO2017-86349-P) y con financiación de SECRETARÍA DE ESTADO DE INVESTIGACIÓN, DESARROLLO E INNOVACIÓN. MINISTERIO DE ECONOMÍA Y COMPETITIVIDAD (Proyecto I+D del Programa Estatal de Fomento de la Investigación Científica y Técnica de Excelencia).

Cómo citar este artículo: Garcia-Moreno J.M. y Feliciano-Pérez, L. (2019) ¿Sigeuen vigentes los modelos teóricos clásicos de la inserción laboral juvenil? En ANDULI, Revista Andaluza de Ciencias Sociales 18 pp. 49-72. DOI: http://dx.doi.org/10.12795/anduli.2019.i18.03 


\section{Introducción}

La tradición en la literatura científica en el ámbito de la Sociología del Trabajo es amplia, tanto como es la preocupación por el estudio del mercado de trabajo, por las variables que explican su funcionamiento y por los elementos que lo definen desde el punto de vista de las barreras de entrada, permanencia y salida en los procesos de inserción laboral (de la población en su conjunto y del colectivo de jóvenes, en particular).

Sin embargo, parece interesante, a la hora de abordar el estudio del mercado de trabajo, utilizar los modelos teóricos clásicos como punto de partida para el establecimiento de modelos teóricos más actuales. Sólo desde el conocimiento de estos modelos - planteamientos teóricos y, sobre todo, entendiendo si sus hipótesis siguen resistiendo el contraste en la actualidad, se puede estar en condiciones de plantear esas otras visiones más actuales, seguramente más complejas en su articulación y en su definición que las primeras.

Este trabajo parte de esta premisa: trabajar con esas teorías clásicas, con sus hipótesis, y tratarlas de verificar en el contexto de la crisis económica, en el marco español y, para un segmento específico, el de los jóvenes ${ }^{1}$. De esta forma, se comprenderá mejor cómo han podido ir evolucionando las diferentes explicaciones al fenómeno social de la inserción laboral. Todos los planteamientos teóricos que se presentan en este artículo encajarían, sin duda, en el concepto mertoniano de teoría de alcance medio (Merton, 1980), dado que no buscarían una asimilación total y universal en relación con la realidad que se quiere explicar, sino que tratan de explicar el punto central de su planteamiento en el contexto de la realidad social donde surgen como teoría. Es decir, se trata de un trabajo en el que se asume que, para comprender mejor la realidad, es bueno mirar a través del cristal de un modelo o planteamiento teórico (Requena y Ayuso, 2016).

No ha lugar a citar aquí la ingente cantidad de trabajos científicos centrados en el trabajo y el mercado laboral en los últimos años, pero baste recordar que, sólo en el período que va de 1995 a 2014, la Revista Española de Investigaciones Sociológicas $(\text { REIS) })^{2}$ (revista de referencia en la sociología en España) dedicó de manera directa a este tema (trabajo y mercado laboral) 49 artículos y, de manera indirecta, en economía o en educación, 132 y 44 artículos respectivamente, sumando estos tres temas por sí solos el 52,1\% de los trabajos presentados en ésta (Trinidad et al, 2016: 49).

Este interés, como es evidente, se ha acrecentado como consecuencia de la crisis económica que se inicia en 2007-2008 y que, en sus consecuencias, se extiende en la última década. En este sentido, centrarse en estudiar el desempleo juvenil en España y la situación de éstos, los jóvenes, en sus procesos de inserción en el contexto actual, lo podemos encontrar, por ejemplo, en trabajos recientes como los de Moreno (2015), García (2014) o Cano (2014). Todos ellos tratan de arrojar luz sobre qué sucede en el mercado laboral español, y cómo se articula la variable desempleo juvenil en este contexto.

1 El debate sobre qué es y qué no es ser joven sigue abierto, pero por falta de espacio no se puede entrar aquí en él, aunque recomendamos la lectura de Bourdieu (2000).

2 Hablamos de la REIS por ser una revista de temas generales en sociología y no específicamente laborales, con la idea de mostrar la importancia de estas temáticas. Evidentemente, en publicaciones especializadas como la Revista Sociología del Trabajo el interés por estos temas es central. 
El contexto de este trabajo es un contexto de crisis económica, tratando de comprender hasta qué punto las principales hipótesis de las teorías clásicas de la inserción laboral pueden seguir siendo validadas en ese citado contexto (de ahí que se utilicen datos de 2006 a 2014). Se toma como referencia teorías cuyas conclusiones pueden parecer simples y poco sofisticadas en la actualidad (donde los modelos explicativos suelen ser tremendamente complejos) pero que, se entiende aquí, siguen teniendo bastante vigencia y siguen permitiendo al observador analizar, interpretar y explicar el proceso de inserción laboral de los jóvenes en España. Es el caso del modelo neoclásico que de forma tan clara explica Toharia (1983), la teoría del capital humano y los planteamientos de Gary Becker (1975) o las teorías credencialistas (Collins, 1986; Thurow, 1983; Rothschild y Stiglitz,1976; Spencer, 1973; Arrow, 1973), así como las ideas de la teoría de la correspondencia (Bowles y Gintis, 1976), la teoría del logro de estatus (Blau y Duncan, 1967) o la teoría del mercado dual de trabajo (Piore, 1983; Doeringer y Piore, 1983).

\section{Metodología}

Para el desarrollo de este artículo se trabaja desde dos estrategias. Por una parte, se revisan los principales modelos clásicos que explican el proceso de inserción laboral para tratar de señalar cuáles son sus principales hipótesis (que desarrollamos a continuación a propósito de cada una de las teorías trabajadas). Y, por otra, partiendo de esas hipótesis, se ha tratado de localizar datos estadísticos (del periodo 2006-2014) y, en la medida de lo posible, relacionados con el segmento de población joven de nuestro país, con el objetivo de tratar de establecer en qué medida alguna de esas hipótesis clásicas sigue teniendo vigencia en el contexto de España y para la población joven.

Así, desde estas estrategias, se ha trabajado con los siguientes planteamientos teóricos y fuentes de datos:

- El modelo neoclásico y su hipótesis sobre cómo un exceso de oferta por parte de los oferentes de empleo presiona a la baja en los salarios cuando esa oferta supera a la demanda de los empleadores. Los datos utilizados provienen de la Encuesta de Población Activa (EPA) presentando las tasas de paro para los cuartos trimestres de los años 2008 y 2014. Así mismo, se ha trabajado con la Encuesta de Estructura Salarial con las medias salariales para 2008 y 2014. Ambas estadísticas son publicadas por el Instituto Nacional de Estadística (INE).

- La teoría del capital humano. Se parte de la hipótesis de que las desigualdades de renta - ingresos de los trabajadores estarían determinadas por desiguales niveles educativos. Para ello se presentan datos de la citada Encuesta de Estructura Salarial (para el año 2014), atendiendo al nivel de estudios y el tipo de contrato (a tiempo completo o a tiempo parcial). Se testan, así mismo, alguna de las hipótesis de Gary Becker en relación con la tasa de rendimiento de la educación universitaria y secundaria. En concreto, se estudia si, para el caso español, hay relación entre ingresos y edad y nivel de estudios - cualificación (se trabaja con la EPA y, en concreto, con tasas de paro para los cuartos trimestres de 2004, 2008 y 2012). Así mismo, se estudia hasta qué punto se confirma la hipótesis de que la población joven es la que vive mayor rotación laboral, y se comprobará si se produce o no el aumento de los años de permanencia en el ámbito educativo (aquí se analizarán datos del Informe de la Juventud en 
España 2012, publicado por el Instituto de la Juventud, y datos del Sistema Estatal de Indicadores de la Educación 2016). Así mismo, se trabaja con otra hipótesis de este planteamiento teórico, aquella que habla de la relación que puede haber entre la inversión en capital humano y el ciclo vital, así como la escasa relación entre ese capital humano - esa formación recibida desde el punto de vista formal, y las definitivas exigencias del mercado laboral que encuentran los jóvenes una vez quieren acceder a dicho mercado (se usan a este respecto datos del Informe de la Juventud en España 2012 y, además, datos del Sondeo de la Juventud Española del Centro de Investigaciones Sociológicas (CIS) Estudio 2.822 de 2009).

- Las teorías credencialistas. Teorías que, en términos generales, se centran en cómo las personas para competir por un puesto de trabajo tratan de conseguir y aportar las mejores credenciales posibles tanto en términos de experiencia como en recursos de tipo ocupacional. Para analizar alguno de estos aspectos se ha trabajado con datos del Sondeo de la Juventud Española del Centro de Investigaciones Sociológicas - Estudio 2.631 de 2006 (previo a la crisis económica y, por tanto, contexto no contaminado por las consecuencias negativas de ésta). Y para analizar si el sistema educativo es usado como filtro por parte de los empleadores a la hora de seleccionar a sus empleados se ha acudido a datos del Observatorio de Innovación en la Educación y en el Empleo con datos del estudio publicado en 2014: Informe OIE sobre jóvenes y mercado laboral: El camino del aula a la empresa.

- La teoría de la correspondencia. Teoría de base marxista que considera, en su concepción amplia, que el sistema educativo participa de forma activa en la reproducción de las condiciones del sistema de producción capitalista. Para trabajar en la idea de correspondencia entre el nivel de estudios alcanzado y el estatus - posición ocupacional de los jóvenes españoles, se analizan datos del Sondeo de la Juventud Española del Centro de Investigaciones Sociológicas Estudio 2.822 de 2009.

- Teoría del logro de estatus. Teoría que trata de establecer que el logro ocupacional alcanzado por los jóvenes dependerá sobremanera de la familia de origen de estos. Se ha analizado, también aquí datos del Sondeo de la Juventud Española del Centro de Investigaciones Sociológicas - Estudio 2.822 de 2009.

- Y, finalmente, la Teoría del mercado dual de trabajo. Desde este planteamiento, el mercado de trabajo es un mercado desigual, segmentado, dualizado, dividido entre aquellos que están en la estabilidad laboral (o en puestos laborales de mayor estabilidad) y, por otro lado, estarían aquellos que describen procesos laborales de precariedad en términos de condiciones de trabajo. Para presentar datos que en relación con los planteamientos de esta teoría se utiliza la Encuesta de Estructura Salarial del INE para el año 2014 y datos Sondeo de la Juventud Española del Centro de Investigaciones Sociológicas - Estudio 2.822 de 2009.

Se puede ver un resumen de las teorías y datos utilizado en la Figura 1. 
Figura 1.- Teorías y fuentes de datos utilizadas

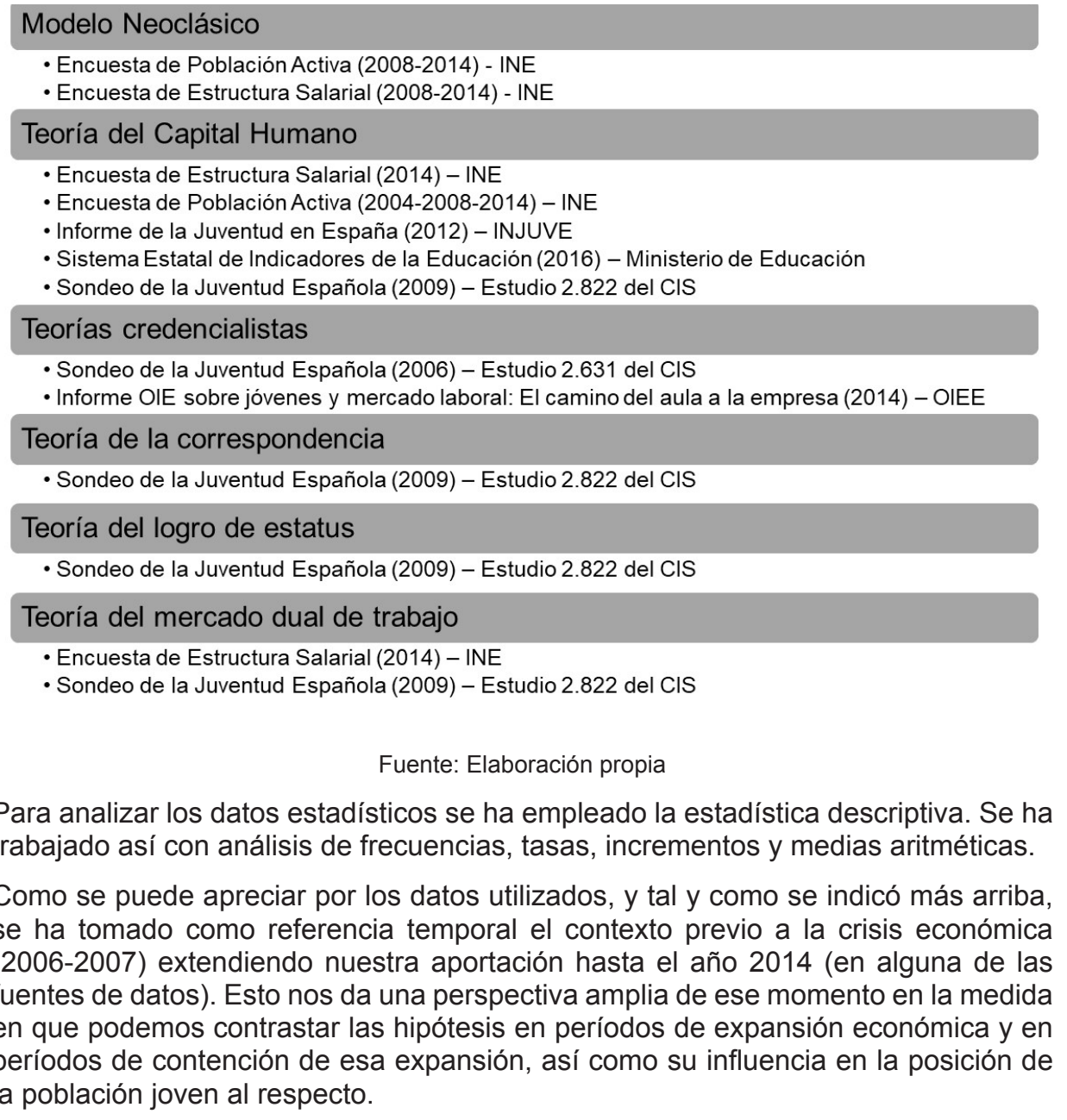

\section{Los modelos clásicos para la inserción laboral}

\subsection{El modelo neoclásico}

El punto de partida del modelo neoclásico es la existencia de un mercado laboral caracterizado por lo que se podría definir como un estado de competencia perfecta. Es decir, es un modelo que apostaría por un equilibrio perfecto entre oferta (de trabajo) y demanda (de trabajo) y, como consecuencia de esta interacción ideal, la definición y aparición del nivel de empleo y el salario de equilibrio (Martínez, 2002: 100).

La demanda de trabajo actuaría como un factor de producción más, de tal forma que el factor humano no tiene más significado que el de un coste fijo, el coste fijo del empleo que procede del reclutamiento, selección y formación de los trabajadores (Toharia,1983). Estos costes fijos actúan como un factor que dificulta la rotación de trabajadores por diferentes puestos de trabajo, limitando, por tanto, la movilidad de los trabajadores. 
Desde este punto de vista, cuando la oferta de trabajo por parte de los trabajadores supera a la demanda de los empleadores, estos presionan a la baja en el coste salarial y, al mismo tiempo, provocan que el nivel de cualificación exigido sea más alto. Es decir, cuando no hay equilibrio entre oferta y demanda lo que se viene a producir es una alteración en los mecanismos de búsqueda tanto de los trabajadores como de los empleadores (Martínez, 2002).

Este planteamiento teórico serviría para explicar algunos componentes del acceso al mercado laboral español por parte de la población joven. Las elevadas tasas de desempleo juvenil que caracterizan a nuestro país frente al contexto de la Unión Europea $^{3}$ (incluso en momento de crecimiento económico) señalan una oferta de empleo de jóvenes normalmente más cualificados que generaciones anteriores, que están en pleno proceso de búsqueda de empleo. Por su parte, ese exceso de oferta frente a la demanda empresarial provoca que los empleadores puedan negociar a la baja los salarios, así como cualquier otra condición laboral.

Tabla 1. Comparación Tasa de Paro y Salario medio (por grupos de edad y período 2008-2014)

\begin{tabular}{|c|c|c|c|}
\cline { 2 - 4 } \multicolumn{1}{c|}{} & Tasa de paro 2014 T4 & Tasa de paro 2008 T4 & Incremento \% \\
\hline De 16 a 19 años & 67,28 & 45,83 & 46,80 \\
\hline De 20 a 24 años & 48,88 & 24,50 & 99,51 \\
\hline De 25 a 29 años & 29,77 & 16,61 & 79,23 \\
\hline De 30 a 34 años & 23,35 & 13,17 & 77,30 \\
\hline Total nacional & 23,70 & 13,79 & 71,86 \\
\hline
\end{tabular}

\begin{tabular}{|c|c|c|c|}
\cline { 2 - 4 } \multicolumn{1}{c|}{} & Salario Medio 2014 $(€)$ & Salario Medio 2008 $(€)$ & Incremento \% \\
\hline Menos de 20 años & $7.732,36$ & $9.960,26$ & $-22,37$ \\
\hline De 20 a 24 años & $11.835,07$ & $13.293,39$ & $-10,97$ \\
\hline De 25 a 29 años & $16.305,61$ & $17.434,00$ & $-6,47$ \\
\hline De 30 a 34 años & $20.208,67$ & $20.528,28$ & $-1,56$ \\
\hline Total nacional & $22.858,17$ & $21.883,42$ & 4,45 \\
\hline
\end{tabular}

Fuente: Elaboración propia con datos de la Encuesta de Población Activa y la Encuesta de Estructura Salarial (INE)

Como se puede ver en la Tabla 1, donde se comparan tasas de paro y salarios en el contexto de la crisis económica iniciada en 2007-2008, el incremento de las tasas de paro ha sido muy alto en todos los grupos de edad analizados. La presión sobre los salarios de esos mismos grupos de edad ha sido a la baja en este período de 6 años (aumento del paro es aumento de la oferta - búsqueda de empleo). Así, en el grupo de 16 a 19 años, mientras que la tasa de paro ha crecido casi en un $50 \%$, el salario se ha visto reducido en un $22,4 \%$. El paro juvenil, en términos de tasa, se incrementó entre 2008 y 2014 en casi el 100\% en el grupo de 20 a 24 años, mientras que el salario medio de ese segmento se redujo en casi un $11 \%$. Además, en comparación con la media total española, vemos cómo la presión al salario a la baja se da en los segmentos más jóvenes, mientras que el salario medio nacional ha aumentado entre 2008 y 2014 a pesar de que la tasa de paro es casi un $72 \%$ mayor.

3 A finales de 2014 EUROSTAT publicó datos de paro juvenil en la UE (tasa de paro de 15 a 25 años). Para el caso de España, la tasa de paro juvenil era del $53,5 \%$ frente a la media de la zona euro del $23,6 \%$, y muy alejado de $7,7 \%$ de Alemania, por poner un ejemplo. 


\subsection{La teoría del capital humano}

El punto básico de este segundo modelo, en lo que al proceso de inserción laboral de los jóvenes se refiere, es que los trabajadores con diferentes niveles de cualificación responden no sólo "a diferencias existentes entre capacidades innatas, sino también, $y$, sobre todo, a que han dedicado cantidades diferentes de tiempo a adquirir esas cualidades" (Toharia,1983:14). Es decir, han dedicado cantidades diferentes de tiempo a adquirir su capital humano. Realizar una inversión en educación rompería con la teoría neoclásica pues ya no se habla sólo de la cantidad de trabajo que se ofrece, sino de la calidad de ese trabajo, calidad que viene determinada por la decisión de cada individuo en relación con la cantidad de capital humano que quiera acumular (Ibídem, 1983) de cara a poder acceder al mercado de trabajo en mejores condiciones.

Esta teoría tiene una forma interesante de explicar las diferencias salariales. Parte de la idea de que, por lo general, los individuos que tienen un nivel educativo alto o de alta cualificación, ganan más dinero que los de nivel educativo bajo o baja cualificación. De esta forma, se explicarían las diferencias salariales atendiendo a las diferentes inversiones en capital humano. Además, señala otro concepto interesante, lo que se conoce como costes de oportunidad. Con ello se refiere a que aquellos que invierten en capital humano estarían sacrificando una posible renta actual en espera de "una renta futura que, necesariamente, debe ser mayor para así compensar los sacrificios realizados" (Toharia, 1983: 14). Por tanto, se puede concluir que, desde esta perspectiva, aquellas actividades que los individuos realizan en el presente podrían afectar a su bienestar futuro en los términos en los que se ha definido: salario.

Gary Becker $(1975,1983)$, el mayor exponente de esta corriente, afirma que las actividades que influyen tanto en la renta monetaria como en la renta física de las personas son las actividades que se materializan como inversiones en capital humano, que encuentran sus principales manifestaciones en la educación, la propia formación que se reciba en el trabajo, así como el proceso de búsqueda de información sobre los precios y las rentas que puedan desarrollar los individuos. Todas estas formas en las que se puede invertir mejoran las cualificaciones de los individuos, y con ello sus niveles de renta. En definitiva, lo que se puede ver en el planteamiento de Becker es que las desiguales rentas e ingresos vendrían determinados por desiguales niveles de educación y formación.

Tabla 2. Ganancia Media por Hora (en €) por trabajador según nivel de estudios (2014) y tipo de contrato

\begin{tabular}{|c|c|c|c|}
\hline Nivel de estudios & $\begin{array}{c}\text { Tiempo } \\
\text { completo }\end{array}$ & $\begin{array}{c}\text { Tiempo } \\
\text { parcial }\end{array}$ & $\begin{array}{c}\text { Media } \\
\text { Nacional }\end{array}$ \\
\hline Menos que primaria & 8,52 & 7,40 & 8,25 \\
\hline Educación primaria & 8,88 & 7,35 & 8,57 \\
\hline Primera etapa de educación secundaria & 9,58 & 7,61 & 9,25 \\
\hline Segunda etapa de educación secundaria & 11,02 & 8,16 & 10,6 \\
\hline Enseñanzas de formación profesional de grado & 12,06 & 8,52 & 11,73 \\
\hline superior y similares & 14,49 & 11,00 & 14,10 \\
\hline Diplomados universitarios y similares & 17,65 & 12,82 & 17,24 \\
\hline Ticenciados y similares, y doctores universitarios & 12,01 & 8,53 & 11,51 \\
\hline
\end{tabular}

Fuente: Elaboración propia con datos de la Encuesta de Estructura Salarial (INE) 
En la Tabla 2, y para el caso de España, se comprueba si es posible mantener aún esa hipótesis de que las desigualdades de renta pueden estar determinadas por desiguales niveles educativos. A menor nivel de estudios y tipo de contrato más precario (tiempo parcial frente a tiempo completo) la ganancia media por hora es menor. Así, mientras que la ganancia media por hora de un trabajador a tiempo completo con nivel de estudios inferior a primaria asciende a $8,52 €$, esa ganancia media sube hasta los $17,65 €$ entre los trabajadores con estudios superiores (licenciatura, doctorado, etc.). Es decir, la inversión en capital humano sigue resultando rentable para el trabajador, al menos, en términos de renta.

Gary Becker $(1975,1983)$, realizó un profundo estudio en Estados Unidos con la pretensión de medir la tasa monetaria del rendimiento de la educación universitaria y secundaria. Llegó a destacadas conclusiones que se señalan de forma resumida por su relación con el objeto de este artículo y que se comprueban también para el caso español:

1.- Existe asociación entre ingresos y edad, aumentando los primeros al aumentar la edad, relación que también es positiva si sumamos la variable nivel de cualificación. Con ello se llega a la idea de que las tasas de paro estarán también relacionadas con el nivel de cualificación.

Tabla 3. Tasas de Paro por nivel de estudios alcanzado (2004-2012) y grupo de edad

\begin{tabular}{|c|c|c|c|c|c|}
\hline Nivel de estudios & & $\begin{array}{l}\text { De } 16 \text { a } \\
19 \text { años }\end{array}$ & $\begin{array}{l}\text { De } 20 \text { a } \\
24 \text { años }\end{array}$ & $\begin{array}{l}\text { De } 25 \text { a } \\
29 \text { años }\end{array}$ & $\begin{array}{l}\text { Media nacio- } \\
\text { nal total }\end{array}$ \\
\hline \multirow{3}{*}{ Educación primaria } & 2012 T4 & 83,38 & 63,05 & 58,12 & 38,98 \\
\hline & $2008 \mathrm{~T} 4$ & 56,33 & 38,86 & 31,15 & 20,36 \\
\hline & 2004 T4 & 31,93 & 20,76 & 15,23 & 11,65 \\
\hline Incremento $2004-2012$ en $\%$ & & 161,13 & 203,71 & 281,62 & 234,59 \\
\hline \multirow{3}{*}{$\begin{array}{l}\text { Educación secundaria primera } \\
\text { etapa y formación e inserción } \\
\text { laboral correspondiente }\end{array}$} & 2012 T4 & 75,94 & 53,89 & 39,44 & 32,83 \\
\hline & 2008 T4 & 44,78 & 27,52 & 21,93 & 17,98 \\
\hline & 2004 T4 & 28,02 & 17,55 & 11,25 & 11,86 \\
\hline Incremento $2004-2012$ en $\%$ & & 171,02 & 207,07 & 250,58 & 176,81 \\
\hline \multirow{3}{*}{$\begin{array}{l}\text { Educación secundaria segunda } \\
\text { etapa y formación e inserción } \\
\text { laboral correspondiente }\end{array}$} & 2012 T4 & 62,57 & 50,70 & 32,95 & 25,31 \\
\hline & 2008 T4 & 35,77 & 20,10 & 15,33 & 13,02 \\
\hline & 2004 T4 & 27,95 & 18,29 & 11,04 & 10,96 \\
\hline Incremento $2004-2012$ en $\%$ & & 123,86 & 177,20 & 198,46 & 130,93 \\
\hline \multirow{3}{*}{$\begin{array}{c}\text { Educación superior, excepto } \\
\text { doctorado }\end{array}$} & 2012 T4 & 28,79 & 42,47 & 25,69 & 16,19 \\
\hline & 2008 T4 & 21,61 & 17,35 & 11,49 & 7,40 \\
\hline & 2004 T4 & 25,20 & 22,70 & 12,38 & 8,06 \\
\hline Incremento 2004-2012 en \% & & 14,25 & 87,09 & 107,51 & 100,87 \\
\hline \multirow{3}{*}{ Doctorado } & 2012 T4 & 0,00 & .. & 35,52 & 5,96 \\
\hline & 2008 T4 & .. & 100,00 & 3,01 & 2,19 \\
\hline & 2004 T4 & .. & .. & 5,02 & 2,82 \\
\hline Incremento $2004-2012$ en $\%$ & & & & 607,57 & 111,35 \\
\hline
\end{tabular}




\begin{tabular}{|c|c|c|c|c|c|}
\cline { 3 - 6 } \multicolumn{2}{|c|}{ Nivel de estudios } & $\begin{array}{c}\text { De 16 a } \\
19 \text { años }\end{array}$ & $\begin{array}{c}\text { De 20 a } \\
24 \text { años }\end{array}$ & $\begin{array}{c}\text { De 25 a } \\
29 \text { años }\end{array}$ & $\begin{array}{c}\text { Media nacio- } \\
\text { nal total }\end{array}$ \\
\hline \multirow{3}{*}{ Total } & 2012 T4 & 73,88 & 51,41 & 33,66 & 25,77 \\
\cline { 3 - 6 } & 2008 T4 & 45,83 & 24,50 & 16,61 & 13,79 \\
\cline { 3 - 6 } & 2004 T4 & 29,04 & 19,31 & 11,95 & 10,53 \\
\hline Incremento 2004-2012 en \% & & 154,41 & 166,24 & 181,67 & 144,73 \\
\hline
\end{tabular}

Fuente: Elaboración propia con datos de la Encuesta de Población Activa (INE)

En este sentido, en España la inversión en capital humano, educación y formación también ayuda a mejorar la posición en el mercado de trabajo. Como se ve en la Tabla 3, desde el año 2004 al año 2012, y para el caso de la población joven española, se aprecia que las tasas de paro son muy diferentes atendiendo al nivel de estudios alcanzado. Por ejemplo, mientras que entre los que tenían 25 a 29 años en 2004 la tasa de paro con nivel de estudios de educación primaria era del 15,23\%, en 2012 esa tasa ascendió al 58,12\% (lo que supone un incremento del $281,62 \%$ ). Frente a ellos, entre los de esa misma edad, pero con Educación Superior (sin contar doctorado) la tasa de paro en 2004 era del 12,38\% (no muy diferente del primer grupo por nivel de estudios), pero en 2014 es del 25,69\% (muy inferior a lo que sucedía en el grupo de educación primaria), lo que es un incremento del 107,51\%. Es decir, la inversión en formación, en capital humano, no asegura no caer en situación de desempleo, pero sí ayuda a estar en mejores condiciones para resistir una situación como la vivida por el mercado laboral español desde finales del año 2007.

2.- Becker concluyó también, para Estados Unidos, que es la población joven la que cuenta con más tendencia a cambiar de empleo con mayor frecuencia, aumentando también los años que permanecen en el ámbito escolar.

Tabla 4.Número de trabajos remunerados (en \%) que han tenido a lo largo de su vida por grupo de edad (2012)

\begin{tabular}{|c|c|c|c|c|}
\cline { 2 - 5 } \multicolumn{1}{c|}{} & 15 a 19 años & 20 a 24 años & 25 a 29 años & Total \\
\hline Uno sólo & 59,3 & 28,8 & 18,4 & 30 \\
\hline 2 & 15,3 & 22,7 & 18,1 & 19,3 \\
\hline 3 & 10,2 & 17,3 & 17,8 & 16,2 \\
\hline 4 & 3,1 & 9 & 11,6 & 9 \\
\hline 5 & 1,9 & 5,6 & 10,4 & 7 \\
\hline 6 & 0,8 & 3,7 & 4 & 3,3 \\
\hline 7 & 0,3 & 1,3 & 2,5 & 1,6 \\
\hline 8 & 0,5 & 1,4 & 2,6 & 1,8 \\
\hline 9 & & 0,9 & 0,7 & 0,6 \\
\hline 10 & 0,3 & 1 & 2,3 & 1,4 \\
\hline 11 & 0,2 & 0,2 & 0,3 & 0,2 \\
\hline 12 & 0,5 & 0,2 & 0,7 & 0,4 \\
\hline No recuerda & 4,9 & 6,9 & 9,1 & 7,4 \\
\hline No contesta & 2,8 & 1,3 & 1,5 & 1,7 \\
\hline Total & 100 & 100 & 100 & 100 \\
\hline
\end{tabular}

Fuente: Elaboración propia con datos del Informe Juventud en España 2012 (Instituto de la Juventud) 
Como se puede ver (Tabla 4.), y con datos del Informe de la Juventud en España 2012 (en pleno contexto de crisis de empleo), el 81,5\% de los jóvenes entrevistados había tenido ya 5 o menos empleos de media, lo que supone una alta rotación por diferentes puestos de trabajo. Además, esa elevada rotación parece que comienza a ser más profunda en los segmentos de población más joven: entre los que tienen 15 a 19 años el porcentaje de los que dicen haber tenido ya 5 o menos empleos remunerados es de casi el $90 \%$ (aunque por la edad, también es el segmento en el que en mayor medida se ha tenido un único empleo), porcentaje que es del 83,4\% entre los que tienen 20 a 24 años, quedando en el 76,3\% entre los que tienen de 25 a 29 años.

Tabla 5.- Esperanza de vida en educación desde los cinco años en España (número de años y período 2007-2014)

\begin{tabular}{|c|c|c|c|c|}
\cline { 2 - 5 } \multicolumn{1}{c|}{} & Hombre & Mujer & Total & $\begin{array}{c}\text { Diferencia Muje- } \\
\text { res - Hombres }\end{array}$ \\
\hline $2007-2008$ & 16,6 & 17,8 & 17,2 & 1,2 \\
\hline $2008-2009$ & 16,4 & 17,5 & 17 & 1,1 \\
\hline $2009-2010$ & 17,1 & 18 & 17,6 & 0,9 \\
\hline $2010-2011$ & 17,6 & 18,4 & 18 & 0,8 \\
\hline $2011-2012$ & 17,8 & 18,6 & 18,2 & 0,8 \\
\hline $2012-2013$ & 18 & 18,7 & 18,3 & 0,7 \\
\hline $2013-2014$ & 18,2 & 18,8 & 18,5 & 0,6 \\
\hline
\end{tabular}

Fuente: Elaboración propia a partir del Sistema Estatal de Indicadores de la Educación.

Edición 2016

Así mismo, y para el caso de España, la estimación del número de años de permanencia de una persona de cinco años (Tabla 5) en el sistema educativo y formativo (en enseñanzas de régimen general no universitaria y universitarias), ha ido creciendo desde el inicio de la crisis económica hasta el último dato analizado (año 2014). Además, si bien las mujeres parecen contar con una mayor esperanza de vida en educación, la distancia respecto a los hombres se ha reducido a la mitad desde 2007-2008 a 2013-2014. En el caso de las mujeres, desde 2007-2008 hasta 20132014, la esperanza de vida en educación ha crecido en un año, mientras que entre los hombres ese mismo dato ha crecido en 1,6 años. Con independencia de esto, sí se aprecia un progresivo aumento de la previsión de permanencia en el sistema educativo (tal y como señalaba el propio Gary Becker), al menos en este período coincidente con la crisis económica. Esta misma idea estaría en la línea desarrollada por Rujas (2015) cuando comenta cómo se ha venido produciendo en España una progresiva vuelta al sistema educativo, como consecuencia del incremento del desempleo, entre aquellos con menores niveles de estudio y, en concreto, cómo se ha producido un incremento de población en la educación secundaria y en los ciclos formativos de Grado Medio en Formación Profesional. Al respecto de este proceso, y como conclusión de su trabajo, indica que "si el retorno de estas personas al sistema escolar no es algo nuevo, parece haberse acentuado como estrategia de protección frente al riesgo de desclasamiento y la precarización creciente que ha traído consigo la crisis económica" (Rujas, 2015: 28).

Este modelo, además, se plantea la relación que tiene la inversión en capital humano y el propio ciclo de vida de las personas. García y Gutiérrez (1996) consideran que existe un hecho fundamental que explica las diferentes carreras laborales de los 
individuos, y éste radica en las desiguales inversiones en capital humano que hacen dichos individuos. Aquellos que hacen más inversión en capital humano tienen mayores probabilidades de conseguir mayores éxitos laborales en el futuro, frente a los que hacen menores inversiones. Esto sitúa el análisis en el camino de otra variable importante: el tiempo que se dedica a esa inversión. Aquellos que invierten más en la acumulación de capital humano, para alcanzar niveles de cualificación más elevados, tardan más en acceder al mercado laboral e inician sus trayectorias laborales de forma más tardía. En todo caso, se puede recordar en este momento lo que se ha podido comprobar para España con los datos presentados en la Tabla 3, y las diferentes tasas de paro atendiendo al nivel de estudios alcanzado, de tal forma que aquellos que realizan mayor inversión en capital humano en términos de mayor nivel de estudios alcanzado, tienen más probabilidades de estar en mejor situación en cuanto a dichas tasas de paro (incluso en momentos de crisis del ciclo económico).

Los ámbitos en los que se toman esas decisiones de cara a la inversión en capital humano variarán dependiendo del momento en el ciclo de vida en el que nos encontramos. García y Gutiérrez (1996), indican que así, por ejemplo, en la infancia y en la adolescencia la inversión se realiza dentro de la familia de origen, donde las decisiones suelen ser tomadas sólo por los padres. A partir de ahí, una vez llega el momento de decidir si se sigue o no en los estudios, si se decide avanzar más allá de la formación obligatoria o acceder al mercado laboral, la familia sigue teniendo un peso importante, pero ya no tan determinante como en la primera etapa, porque estaríamos hablando de decisiones clave en el futuro de los hijos como puede ser elegir la ocupación.

La última etapa es la que se inicia con la entrada al mercado laboral de los jóvenes y, con ello, a los primeros empleos. Aquí se siguen tomando decisiones de cara a la inversión en capital humano, decisiones que se centrarán más en relación con los puestos de trabajo (García y Gutiérrez, 1996). En este caso, en el mercado de trabajo español y, en concreto, en el que deben insertarse los jóvenes, existe un desajuste entre la formación y la cualificación con la que se llega y las exigencias de ese mercado. Esto hace que las inversiones en capital humano estén destinadas a la especialización y al progresivo ajuste a esas necesidades requeridas en el mundo laboral. En este marco es en el que adquiere sentido la formación de postgrado, la formación en la empresa, la formación en el trabajo, etc. Las decisiones en este caso, frente a lo que plantean García y Gutiérrez, no siempre se toman ya en el ámbito de la propia familia tras la emancipación residencial, sino que, en el caso de España, son decisiones que se siguen realizando en conjunto con la familia de origen, pero con mayor peso específico para el joven protagonista de la decisión, ya que las tasas de emancipación residencial antes de los 30 años en España no parecen indicar que se actúe de forma contraria. De hecho, en el cuarto trimestre del año 2014, la tasa de emancipación entre la población joven española de entre 16 y 29 años era del 21,5\%, y más de un $60 \%$ de los jóvenes españoles, según el citado Informe de la Juventud en España 2012, vivía en casa de sus padres la mayor parte del año.

Profundizando un poco más en el caso español, ya se ha apuntado la idea de la escasa relación entre lo estudiado en el sistema educativo y las exigencias del mercado laboral. Pues bien, preguntados aquellos, que en su mayoría ya habrían acabado su etapa formativa formal (los jóvenes que tienen entre 25 y 29 años), sobre si su trabajo actual estaba relacionado o no con su nivel de estudios, se comprueba cómo el $60,4 \%$ de los jóvenes entrevistados señala que está poco o nada relacionado (Tabla 6 ), lo que se convierte en el síntoma del desajuste entre la formación y las exigencias del mercado laboral, tal y como se indicó más arriba. 
Tabla 6.- Grado de relación del empleo actual con los estudios realizados (\%) y para jóvenes de 25 a 29 años

\begin{tabular}{|c|c|}
\cline { 2 - 2 } \multicolumn{1}{c|}{} & Grado de relación \\
\hline Muy relacionado & 23,3 \\
\hline Bastante relacionado & 17,7 \\
\hline Poco relacionado & 16,9 \\
\hline Nada relacionado & 43,5 \\
\hline N.C. & 0,6 \\
\hline
\end{tabular}

Fuente: Elaboración propia con datos del Sondeo de la Juventud Española - Segunda Oleada - 2009 - Estudio 2822 (CIS)

\subsection{Las teorías credencialistas}

Los jóvenes compiten con otros jóvenes por alcanzar un puesto de trabajo. Para ello buscan algún tipo de credencial que les permita estar en mejores condiciones en ese proceso competitivo. Por lo general, y en la esencia de este planteamiento clásico, dichas credenciales se obtendrían tanto a través del sistema educativo como mediante la adquisición de experiencia profesional en el ámbito laboral. Se describiría así una estructura social que se definiría por la adquisición de mejores posiciones de estatus y donde el mérito alcanzado sería el principal factor explicativo del logro laboral, del logro ocupacional (Collins, 1986).

La Teoría de la competencia por los Puestos de Trabajo, que fue planteada por Thurow (1983), es uno de los exponentes de esta corriente credencialista. Desde su punto de vista, la competencia entre los trabajadores se produciría sobre todo por los puestos de trabajo y, en menor medida, por los salarios. En un escenario de competencia constante por dichos puestos, la experiencia alcanzada, así como la formación que reciban los trabajadores devendrán en recursos ocupacionales, entendidos estos como mejores credenciales y como vía de acceso a puestos laborales de mayor prestigio.

Según Brunet y Morell (1998: 49), la aportación de Throw se basaría también en la idea de que la competencia por los puestos de trabajo se fundamentaría en que las cualificaciones que se aplican en la actividad laboral se consiguen de manera "informal en el propio puesto de trabajo, lo que lleva aparejado que la productividad individual no dependa tanto de las condiciones iniciales del trabajador como del puesto de trabajo en concreto", lo cual ayudaría a la obtención de cualificaciones y/o mejores credenciales. Esas mejores credenciales son las que facilitarán al empresario cubrir las vacantes mediante la clasificación de los candidatos en relación con el coste que supondría en potencia el proceso de aprendizaje de cada empleado. En definitiva, lo que viene a indicar esta aportación es que la mayoría de las cualificaciones laborales se adquirirán una vez se llega al puesto de trabajo y no antes (García y Gutiérrez, 1996), de ahí la importancia que tiene el acceso al mercado de trabajo para adquirir experiencia laboral.

¿Y cómo se puede ver hasta qué punto funcionan estas ideas de las teorías credencialistas para el caso español? Pues bien, los propios jóvenes españoles (Tabla 7), preguntados por cuáles son las razones por las que existe paro juvenil en nuestro país, señalan la falta de experiencia como la principal razón por la que los empresarios no contratan personas jóvenes y, en menor medida, la inadecuada formación recibida. Sin embargo, el $20 \%$ de los jóvenes que respondieron en el estudio $n^{\circ} 2631$ del Centro de Investigaciones Sociológicas (previo a la crisis económica, de ahí lo significativo de las opiniones que tiene este segmento de población precisamente en este contexto) sí indican que, a la hora de elegir los estudios, los jóvenes no piensan 
en sus salidas profesionales. Así se configuran dos tipos de barreras de entrada al mercado laboral para los jóvenes españoles: las que ponen los propios empresarios a la hora de no contratar a población joven por falta de la experiencia y, con ello, dejan de conseguir las credenciales en el puesto de trabajo; y, por otra parte, las que ponen los propios jóvenes al decidir estudiar algo que puede no tener cabida - salida laboral en un mercado de trabajo como el español, lo que redundaría en lo planteado con anterioridad a propósito de la teoría del capital humano.

Tabla 7. Razones que explican el paro juvenil en España (\%) por grupos de edad

\begin{tabular}{|c|c|c|c|c|}
\cline { 2 - 5 } \multicolumn{1}{c|}{} & $\begin{array}{c}15 \text { a } 19 \\
\text { años }\end{array}$ & $\begin{array}{c}20 \text { a } 24 \\
\text { años }\end{array}$ & $\begin{array}{c}25 \text { a } 29 \\
\text { años }\end{array}$ & Total \\
\hline $\begin{array}{c}\text { Los empresarios no dan empleo a gente sin } \\
\text { experiencia }\end{array}$ & 39 & 40,7 & 37,9 & 39,2 \\
\hline La formación que reciben no es la adecuada & 16,1 & 17,4 & 19,7 & 17,9 \\
\hline En la elección de estudios no piensan en las salidas & 24,1 & 19,5 & 19,1 & 20,7 \\
\hline Los contenidos de FP no son adecuados & 11,6 & 14,6 & 15,9 & 14,2 \\
\hline N.S. & 7 & 5,4 & 5,7 & 6 \\
\hline N.C. & 2,2 & 2,4 & 1,7 & 2,1 \\
\hline Total & 100 & 100 & 100 & 100 \\
\hline
\end{tabular}

Fuente: Elaboración propia con datos del Sondeo de la Juventud Española - Estudio 2631- 2006 (CIS)

Junto al planteamiento de Throw tenemos la Teoría del Filtro de Spence (1973), la Teoría de la señalización de Arrow (1973) y la Teoría de selección o criba de Rothschild y Stiglitz (1976). Todas inciden en que la formación no tiene por qué llevar aparejada una mayor productividad. Así mismo, apuntan en la dirección de señalar el papel del sistema educativo en su función de selección de los mejores. Sería un sistema educativo que clasificaría a los individuos jóvenes trabajadores. Dicha clasificación sería información valiosa para el futuro empleador que podrá desarrollar de manera mucho más eficaz la labor de selección entre la oferta existente. De esta forma, el nivel educativo actuaría como la forma y el medio para acceder al mercado laboral y, en consecuencia, el camino por el cual conseguir unos salarios adecuados al puesto desempeñado. En definitiva ¿qué papel tiene el sistema educativo? Filtrar para poder seleccionar a los mejores, entendiendo por mejores aquellos que el empleador considera más adecuados a los objetivos de su empresa.

Profundizando un poco más en esta interesante perspectiva, Spence (1973) define un modelo básico de equilibrio como feedback informativo en el que la oferta salarial de los empleadores a los diferentes niveles educativos induce a los individuos a invertir en educación. Por su parte, Arrow (1973) desarrolla la teoría de la educación en el contexto de la educación superior la cual sirve, esencialmente, como instrumento de filtro para clasificar a los individuos y aportar información al mercado de trabajo.

En este sentido, existe, para el caso de España un interesante informe que abunda en estas cuestiones y, en concreto, en la educación superior desde el punto de vista tanto de los trabajadores jóvenes como de los empresarios. Nos referimos al trabajo del Observatorio de Innovación en la Educación y en el Empleo: Informe OIE sobre jóvenes y mercado laboral. El camino del aula a la empresa (2014). Por una parte, destaca la desconfianza, desconfianza de los jóvenes españoles hacia la posibilidad de ejercer su profesión en España, posicionándose así el $80 \%$ de los universitarios españoles que participaron en el estudio y que dicen tener bajas expectativas al respecto. En relación con el 
perfil de formación que, en opinión de los jóvenes, buscan las empresas españolas, más de dos tercios de los jóvenes universitarios encuestados consideran que los perfiles buscados por dichas empresas son muy exigentes. Además, sólo el $40 \%$ de las empresas que participaron en la investigación señalan que la formación universitaria recibida por los candidatos a un puesto de trabajo en España es completa. Además, son los propios jóvenes los que vienen a indicar que carecen, desde el sistema educativo, de competencias básicas y cada vez más necesarias para la inserción laboral, con lo que esa idea de filtro señalada anteriormente no se materializaría en el contexto español al nivel deseado, puesto que las empresas no cuentan con elementos que requerirían para aplicar dicho filtro (competencias buscadas y que no se encuentran en el grado deseado). Por ejemplo, el $75 \%$ de las empresas considera que los jóvenes españoles no reciben formación adecuada en idiomas, un $71 \%$ en prácticas en empresa ${ }^{4}$, un $69 \%$ considera inadecuada la formación en habilidades y capacidades (caso de la iniciativa, la motivación, la capacidad para resolver problemas o el trabajo en equipo), el $62 \%$ considera que no es suficiente la internacionalización de los estudiantes y un $34 \%$ que tampoco es buena la formación en informática y nuevas tecnologías. Por tanto, inadecuación de la formación al mundo del trabajo tanto desde el punto de vista de los jóvenes como de los empleadores, de tal forma que, si bien el empleador sigue usando el sistema educativo para señalar, filtrar, analizar las credenciales, le gustaría poder hacerlo no sólo en base a conocimientos propios de un currículum formativo, sino también en relación con otras competencias cada vez más demandadas (como las que se acaban de señalar).

\subsection{La teoría de la correspondencia}

Se trata de un planteamiento de base marxista en su concepción del propio sistema educativo, en la medida en la que consideran que éste lo que hace es reproducir las condiciones del propio sistema de producción capitalista. Los principios básicos de esta teoría los definieron Samuel Bowles y Herbert Gintis (1976). Su planteamiento es muy conocido, y se basa en la idea de que las relaciones sociales que se generan tanto en la familia como en el entorno de la escuela no tienen más correspondencia que las propias relaciones de producción. El centro escolar crea trabajadores que presentan las características exigidas en los diferentes puestos de trabajo que haya en un determinado mercado laboral. Por ejemplo, si dicho mercado laboral necesita jóvenes con capacidad de decisión, así serán formados algunos y, a partir de ahí, ocuparán los puestos más elevados de la jerarquía ocupacional, al tiempo que se formará en la obediencia y el respeto a las normas a aquellos que el sistema productivo necesite que ocupen los puestos más bajos de esa misma jerarquía ocupacional. Esta particular visión del papel del sistema educativo como productor de desigualdad se refuerza con otra desigualdad: los recursos económicos de las familias. Dichos recursos se encuentran desigualmente repartidos y actuarán como mecanismos de refuerzo a esta educación diferenciada según el puesto futuro que se espera sea ocupado.

Desde aquí se llega a otra de las hipótesis de Bowles y Gintis, que no es más que aquella que indica que existe correspondencia entre las relaciones sociales que se producen / generan dentro de la familia y las relaciones de producción. Aplicada esa actuación diferenciada del sistema educativo al caso de la familia, el proceso es tal que los padres que ocupan una posición baja en la jerarquía ocupacional valorarán aquello en lo que ellos mismos fueron formados (obediencia, respeto a la norma, la honradez, por ejemplo), mientras que aquellos padres que tienen una posición de estatus laboral más alta tendrán mayor inclinación hacia valores como "la curiosidad, la autodirección y la felicidad" (1976: 88).

4 Se puede ver un interesante trabajo al respecto de las prácticas en empresa en Vázquez-Fernández y Barrera-Algarín (2017). 
El sistema educativo tiene, por tanto, la función de "integrar a los jóvenes en el sistema económico de la correspondencia estructural entre sus relaciones sociales y las de producción" (Brunet y Morell, 1998: 52). Esto quiere decir que es el sistema educativo el que amolda a los individuos a los principios de la disciplina en el puesto de trabajo, pero también coadyuva a que los trabajadores jóvenes desarrollen características de comportamiento personal que terminan siendo marcas identificativas de la clase social de pertenencia, identificación que es también con un determinado puesto de trabajo (Brunet y Morell, 1998).

Bowles y Gintis, profundizando en este papel básico atribuido al sistema educativo, señalan que lo que ha caracterizado a la organización educativa es la de convertirse en el espacio para la réplica de las relaciones de dominio, así como las relaciones de subordinación que tienen lugar en la esfera económica.

"La correspondencia entre la relación social de la instrucción escolar y el trabajo explica la capacidad que tiene el sistema educativo para producir una fuerza de trabajo dócil y fragmentada. La experiencia de la instrucción escolar, y no meramente el contenido del aprendizaje formal es central en el proceso" (Bowles y Gintis, 1985: 145).

Tabla 8. Correspondencia del nivel de estudios más alto alcanzado por jóvenes de 25 a 29 años y la ocupación alcanzada (\%)

\begin{tabular}{|c|c|c|c|c|c|c|}
\hline \multirow[b]{2}{*}{ Ocupación Alcanzada } & \multicolumn{6}{|c|}{ Nivel de estudios } \\
\hline & Primaria & $\begin{array}{l}\text { Secun- } \\
\text { daria }\end{array}$ & F.P. & $\begin{array}{l}\text { Medios uni- } \\
\text { versitarios }\end{array}$ & $\begin{array}{l}\text { Supe- } \\
\text { riores }\end{array}$ & Total \\
\hline $\begin{array}{c}\text { Dirección de empresas y admi- } \\
\text { nistraciones públicas }\end{array}$ & 2,5 & 6,2 & 6,4 & 8,9 & 1,6 & 4,6 \\
\hline $\begin{array}{c}\text { Técnicos y profesionales cien- } \\
\text { tíficos e intelectuales }\end{array}$ & & & 1,1 & 40 & 51,6 & 13,1 \\
\hline $\begin{array}{c}\text { Técnicos y profesionales de } \\
\text { apoyo }\end{array}$ & 8,3 & 13,8 & 17 & 17,8 & 22,6 & 14,9 \\
\hline $\begin{array}{l}\text { Empleados de tipo } \\
\text { administrativo }\end{array}$ & 4,2 & 6,2 & 4,3 & 2,2 & 4,8 & 4,4 \\
\hline $\begin{array}{l}\text { Trabajadores de servicios de } \\
\text { restauración y personales }\end{array}$ & 25 & 36,9 & 26,6 & 17,8 & 4,8 & 23,2 \\
\hline $\begin{array}{c}\text { Trabajadores cualificados de } \\
\text { agricultura y pesca }\end{array}$ & 4,2 & & 3,2 & 2,2 & & 2,6 \\
\hline $\begin{array}{l}\text { Artesanos y trabajadores cuali- } \\
\text { ficados de la industria }\end{array}$ & 23,3 & 16,9 & 26,6 & 4,4 & 4,8 & 17,8 \\
\hline $\begin{array}{l}\text { Operadores de maquinaria y } \\
\text { montadores }\end{array}$ & 12,5 & 6,2 & 8,5 & & 1,6 & 7,2 \\
\hline Trabajadores no cualificados & 19,2 & 10,8 & 4,3 & 4,4 & 6,5 & 10,3 \\
\hline Fuerzas armadas & 0,8 & 3,1 & 1,1 & & & 1 \\
\hline N.C. & & & & 1,1 & 2,2 & 1,6 \\
\hline Total & 100 & 100 & 100 & 100 & 100 & 100 \\
\hline
\end{tabular}

Fuente: Elaboración propia con datos del Sondeo de la Juventud Española - Segunda Oledada - 2009 - Estudio 2822 (CIS) 
En el caso español, y para aquellos jóvenes que, en toda lógica y por edad, ya habrían acabado el periodo educativo formal (aquellos con edad comprendida entre los 25 y 29), se presenta en la Tabla 8 la correspondencia entre el nivel educativo alcanzado y el puesto ocupado (por grandes grupos laborales). Más allá de las excepciones (es decir, posiciones laborales ocupadas por niveles de estudios, en teoría, no siempre acordes, lo que indicaría sobre-cualificación o infra-cualificación) lo que sí se puede comprobar es que hay una importante correspondencia entre lo estudiado y el tipo de trabajo que se ocupa. Por ejemplo, son los que tienen estudios universitarios medios o superiores los que en mayor medida ocupan posiciones de técnicos profesionales, científicos y de profesionales de apoyo. Y son los que tienen educación primaria y secundaria los que en mayor medida ocupan las posiciones laborales centradas en la artesanía, el trabajo cualificado industrial, el operador de maquinaria y/o el trabajo no cualificado. Es decir, el sistema educativo, el nivel alcanzado por los jóvenes españoles, vendría a reproducir las clases sociales vinculadas a la formación por la vía de la ocupación alcanzada.

\subsection{Teoría del Logro de Estatus}

Peter M. Blau y Otis Dudley Duncan desarrollan la Teoría del Logro de Estatus en su ya clásico texto The American Occupational Structure (1967). El planteamiento de estos autores sigue sobre el terreno del papel jugado por la educación y su influencia en el logro ocupacional de los individuos (en nuestro caso, los jóvenes). Sin embargo, tanto el paso por el sistema educativo como el nivel que se alcance dependerá de la familia de origen de ese joven. Blau y Duncan lo que hacen es construir una hipótesis que afirma que el papel que tiene la educación es la de actuar de intermediaria entre la propia familia y el logro ocupacional alcanzado.

Junto con la educación, y mediante el Path Analysis, señalan otras variables que también tienen peso en ese logro ocupacional. Así estaría el caso la inteligencia de los sujetos, la motivación y, en especial, las influencias que tenga sobre ellos el contexto social en el que se mueven. Serían también variables consideradas la edad, características del primer empleo como el nivel ocupacional, la existencia o no de cambios de residencia (movilidad residencial o disponibilidad a ella), etc. Desde aquí, Blau y Duncan llegaron a conclusiones que, durante largo tiempo, han constituido hipótesis a contrastar en estudios de inserción laboral. Alguna de ellas son las siguientes (Hernández, 1993):

1.- Hay, y queda definida, una clara correlación en cuanto a la influencia que tiene, en el estatus ocupacional que se alcanza en un momento determinado, el estatus ocupacional que se haya conseguido en momentos anteriores de la vida laboral. Es decir, en el fondo apuntan ya al concepto de trayectorias laborales que, por falta de espacio, no vamos a poder desarrollar aquí en la extensión deseada, pero que queda perfectamente explicado para el caso de los jóvenes españoles en los también ya clásicos trabajos de Joaquín Casal (1996; 1999), donde se establecen los modos de transición a la vida adulta. Señala como las más frecuentes a futuro (el trabajo de Casal alude a los umbrales del S.XXI) las trayectorias en precariedad (entendidas éstas como una especie de inestabilidad contante en el proceso de inserción laboral) y las trayectorias de aproximación sucesiva (entendidas como una especie de proceso de ensayo - error en el mercado de trabajo mediante el ajuste de expectativas constante y la progresiva asunción de los logros ocupacionales - profesionales parciales). Esta última, la de aproximación sucesiva, es la que validaría para España esta hipótesis de Blau y Duncan. 
2.- Señalan que no hay excesiva correlación intergeneracional entre movilidad ocupacional y movilidad educacional. Es decir, hay casos en los que el nivel educativo del padre o la madre (por ejemplo, bajo) no determina una ocupación baja en la jerarquía ocupacional de los hijos, sino lo contrario y, con ello, la posibilidad de dar a los hijos jóvenes una mejor educación aumenta, creciendo también las posibilidades de los hijos de mejorar en sus posiciones ocupacionales.

En la Tabla 9 se presentan datos para el caso de los jóvenes españoles en relación con lo que se acaba de indicar. Se puede apreciar que, habiendo una relativa reproducción de clase social ocupacional a partir del nivel de estudios de los padres (es decir, por ejemplo, entre padres de estudios superiores aparecen ocupaciones más altas en el caso de los hijos), sí se ve también cómo no son nada despreciables los porcentajes de hijos que ocupan posiciones de técnico y profesional científico o profesional de apoyo teniendo sus padres niveles de estudio inferiores a primaria o únicamente primaria. En todo caso, esta hipótesis se estaría matizando en España, en la medida en que cada vez son más las generaciones de padres - madres que contando con estudios superiores tienen hijos llegando a la edad de inserción laboral también con niveles de estudios altos (recordemos el aumento descrito con anterioridad de la esperanza de vida en la educación).

Tabla 9.- Relación entre el nivel de estudios más alto alcanzado por el padre y la ocupación alcanzada por los jóvenes de 25 a 29 años (\%)

\begin{tabular}{|c|c|c|c|c|c|c|c|}
\hline \multirow[b]{2}{*}{ Ocupación Alcanzada } & \multicolumn{7}{|c|}{ Nivel de estudios del Padre } \\
\hline & $\begin{array}{c}\text { Menos de } \\
\text { estudios } \\
\text { primarios }\end{array}$ & Primarios & $\begin{array}{l}\text { Educa- } \\
\text { ción se- } \\
\text { cundaria }\end{array}$ & $\begin{array}{l}\text { Estudios } \\
\text { superio- } \\
\text { res }\end{array}$ & N.S. & N.C. & Total \\
\hline $\begin{array}{l}\text { Dirección de empresas y } \\
\text { administraciones públicas }\end{array}$ & 8,5 & 4,6 & 3,3 & 3,6 & 6,3 & & 4,6 \\
\hline $\begin{array}{l}\text { Técnicos y profesionales } \\
\text { científicos e intelectuales }\end{array}$ & 10,6 & 7,5 & 20,7 & 25 & & & 13,1 \\
\hline $\begin{array}{c}\text { Técnicos y profesionales de } \\
\text { apoyo }\end{array}$ & 12,8 & 12,7 & 20,7 & 19,6 & & & 14,9 \\
\hline $\begin{array}{l}\text { Empleados de tipo } \\
\text { administrativo }\end{array}$ & 2,1 & 5,8 & 3,3 & 3,6 & & 25 & 4,4 \\
\hline $\begin{array}{l}\text { Trabajadores de servicios de } \\
\text { restauración y personales }\end{array}$ & 19,1 & 27,7 & 18,5 & 19,6 & 18,8 & 50 & 23,2 \\
\hline $\begin{array}{c}\text { Trabajadores cualificados de } \\
\text { agricultura y pesca }\end{array}$ & 6,4 & 2,3 & 2,2 & & 6,3 & & 2,6 \\
\hline $\begin{array}{l}\text { Artesanos y trabajadores } \\
\text { cualificados de la industria }\end{array}$ & 17 & 20,2 & 15,2 & 10,7 & 37,5 & & 17,8 \\
\hline $\begin{array}{l}\text { Operadores de maquinaria y } \\
\text { montadores }\end{array}$ & 4,3 & 11 & 5,4 & 1,8 & 6,3 & & 7,2 \\
\hline Trabajadores no cualificados & 17 & 7,5 & 10,9 & 8,9 & 18,8 & 25 & 10,3 \\
\hline Fuerzas armadas & 2,1 & 0,6 & & 1,8 & 6,3 & & 1 \\
\hline N.C. & & & & 5,4 & & & 0,8 \\
\hline Total & 100 & 100 & 100 & 100 & 100 & 100 & 100 \\
\hline
\end{tabular}

Fuente: Elaboración propia con datos del Sondeo de la Juventud Española - Segunda Oledada - 2009 - Estudio 2822 (CIS) 
3.- Lo que sí vienen a indicar en relación con la movilidad social intergeneracional es que a medida que aumenta el estatus del padre las posibilidades de movilidad ascendente de los hijos disminuyen, lo cual es del todo lógico en la medida en que disminuyen las posiciones sobre las que se puede producir dicha movilidad (completando así lo último indicado al respecto del punto 2.). Esta conclusión, pero matizada para las últimas generaciones, también se ha reproducido en España y, de forma clara, se puede encontrar en Martínez y Marín (2012). Explican cómo han sido los procesos de movilidad social en nuestro país en las últimas décadas, y cómo la propia movilidad social para las cohortes de nacidos entre 1977-1981 (la última que analizan a partir del Estudio $n^{\circ} 2.634$ Clases Sociales y estructura social del CIS del año 2006), los que, en teoría, deberían haber completado ya su proceso de inserción social, ha sufrido una caída en su movilidad social ascendente en relación a generaciones anteriores, y han vivido, por otra parte, un aumento de su movilidad social descendente. Como consecuencia de la crisis, contexto de este trabajo, es cada vez más frecuente encontrar hijos con peor posición de estatus que su familia de origen.

En este punto tenemos también a Collins (1986), quien está a medio camino entre los planteamientos credencialistas (apartado anterior) y los que hablan del logro de estatus. Collins plantea que es la educación la que hay que considerar como un elemento que terminará posicionando a las personas en un determinado grupo de estatus. Esto quiere decir, en su opinión, que la educación deja de cumplir un papel destinado al logro ocupacional por la vía de la cualificación, para cumplir un papel de desarrollo de una función de selección cultural. En suma, siendo importante el nivel educativo alcanzado (en términos de titulación, hemos de entender), con dicho nivel no es suficiente puesto que será también fundamental contar con el proceso de socialización del que ha participado el individuo para la aprehensión de habilidades y destrezas que serán absolutamente necesarias en el futuro laboral. Collins relacionará también dicha socialización con la productividad individual, de tal forma que aquellos que han completado con éxito esa socialización en habilidades y destrezas, una vez lleguen al mundo laboral, acabarán siendo más productivos. En este sentido, cobran de nuevo vigencia las conclusiones presentadas anteriormente en relación con el Observatorio de Innovación en la Educación y en el Empleo.

\subsection{La teoría del mercado dual de trabajo}

Sin duda, uno de los planteamientos más clarificadores de la descripción de las estructuras de los mercados laborales en las sociedades postindustriales es el de Michael J. Piore (1983). Según su teoría del mercado dual de trabajo, éste está segmentado de tal forma que, por una parte, estaría un sector primario caracterizado porque es capaz de ofrecer puestos laborales en los que los salarios son relativamente altos, en los que las condiciones laborales son buenas, las situaciones y las relaciones laborales se establecen en planos de igualdad, las normas laborales son respetadas y el ejercicio de éstas está perfectamente definido. Son trabajos en los que las posibilidades de avanzar y crecer son reales. En definitiva, esto alude a la estabilidad laboral como marca característica de este segmento del mercado laboral.

Pero, por otra parte, habla de la existencia de un sector secundario que quedaría definido por características totalmente opuestas a las que se acaba de indicar para el primario. Esto es, peores condiciones de trabajo y, evidentemente, peores salarios. Posibilidades de avance limitadas cuando no inexistentes. Esto indica una enorme rotación laboral de la población que está en ese segmento del mercado de trabajo, tal y como se pudo comprobar anteriormente en la Tabla 4, cuando se presentó el 
número de empleos remunerados de los jóvenes españoles y la inestabilidad en el empleo como signo distintivo de esta población.

Sarriés (1999) alude a cómo entre las características del mercado laboral está la de ser discriminatorio y opaco ante determinados perfiles, perfiles que García (1998), al tratar ese sector secundario, concretiza en mujeres, jóvenes, inmigrantes y minorías étnicas, perfiles que son los que, en mayor medida, experimentan esas peores condiciones laborales descritas por Piore en su visión dual del mercado de trabajo.

El salario, la ganancia por hora trabajada puede ser, sin duda, un ejemplo de esa dualidad del mercado de trabajo. En la Tabla 10 se comprueba cómo la ganancia media por hora en España aumenta a medida que aumenta la edad (tal y como señalaba el propio Gary Becker y que ya se vio en su momento). Así, de los 7,42€ de ganancia media por hora trabajada entre los menores de 25 años, se llega a los $13,39 €$ de ganancia por hora entre los que tienen 55 y más años. No es sólo una diferencia por edad, sino que esta dualidad del mercado de trabajo aparece también por el tipo de contrato: se gana menos por hora de trabajo no sólo si se es más joven, sino si se está ante un contrato a tiempo parcial o frente a un contrato a tiempo completo. Esa diferencia es menor entre los más jóvenes independientemente del contrato, pero en el caso de las personas de más de 55 años, los que tienen un contrato a tiempo completo ganan de media por hora trabajada $13,89 €$, mientras que los de esa misma edad con un contrato a tiempo parcial se quedan por debajo de los $10 €$ de ganancia por hora. Esa dualidad de nuestro mercado de trabajo queda claramente representada, por tanto, en estos datos de la Encuesta de Estructura Salarial para el año 2014.

Tabla 10.Ganancia Media por Hora (en $€$ ) por trabajador por edad (2014) y tipo de contrato

\begin{tabular}{|c|c|c|c|}
\cline { 2 - 4 } \multicolumn{1}{c|}{} & Tiempo completo & Tiempo parcial & Media Nacional \\
\hline Menos de 25 años & 7,5 & 7,27 & 7,42 \\
\hline De 25 a 34 años & 10 & 8,12 & 9,67 \\
\hline De 35 a 44 años & 12,04 & 8,76 & 11,59 \\
\hline De 45 a 54 años & 12,99 & 8,56 & 12,47 \\
\hline 55 y más años & 13,89 & 9,57 & 13,39 \\
\hline Todas las edades & 12,01 & 8,53 & 11,51 \\
\hline
\end{tabular}

Fuente: Elaboración propia con datos de la Encuesta de Estructura Salarial (INE)

Martínez (2000: 78) utiliza también esta perspectiva en su trabajo e indica, por una parte, que "la ubicación de los trabajadores en un segmento u otro está determinado por las características del puesto de trabajo en relación con la cualificación del trabajador" y, por otra parte, que "las habilidades, oportunidades y expectativas de adquirir educación formal están determinadas por la procedencia de clase social”, lo que, en último término, está claramente relacionado con el estatus de la familia de origen, esencialmente en el acceso a los primeros empleos. Todos estos aspectos también han sido descritos con anterioridad tanto en la Tabla 8 como en la Tabla 9, y los factores de reproducción de clase social origen - destino.

El propio Piore amplía su perspectiva (1983) y afirma que, incluso dentro del sector primario (el más estable en términos laborales), habría una subdivisión interna: segmento inferior y segmento superior. Dentro del segmento superior del sector primario estarían encuadrados los trabajadores profesionales y directivos. Ambos segmentos se diferenciarían en que en el superior los salarios son más elevados, el estatus 
asociado a dichas posiciones también lo es y las posibilidades de que se produzcan ascensos profesionales son mayores que en el segmento primario inferior. Es un segmento, el superior primario, que se parecería al secundario (el de la precariedad laboral, como se definiría en la actualidad, y para el caso español, como el elemento característico) en lo que a la movilidad y a la rotación por diferentes puestos de trabajo se refiere, pero mientras que en el secundario es rotación en la inestabilidad, la temporalidad y la falta de expectativas de promoción, en el primario superior, es una movilidad y rotación para la promoción y el ascenso profesional.

El propio autor señala que hay barreras de entrada al segmento superior. La principal es la educación formal. La educación formal pasa a convertirse en un requisito básico para poder llegar a obtener un puesto de trabajo en el segmento superior (como también se pudo ver en los datos anteriores al señalar cierta correspondencia entre nivel de estudios y estatus ocupacional entre los jóvenes españoles). De esta forma, esos requisitos educativos que, por lo general, pueden ser esquivados en otros ámbitos de la economía, variarán con los propios ciclos económicos, con las propias condiciones económicas, pudiendo ser sustituidos a conveniencia por otros equivalentes en formación informal o la propia experiencia. En definitiva, lo que indica Piore es cómo el segmento superior es capaz de establecer mecanismos de acceso al mismo que, en no pocas ocasiones, se terminan convirtiendo en barreras absolutas de entrada para aquellos que no dispongan de ellos (aludimos así al propio concepto sociológico de Cierre Social Excluyente desarrollado por Parkin (1984).

Cuando Doeringer y Piore (1983) hablan de los jóvenes de forma específica, vienen a considerar que existe un discurso mayoritario que se construye sobre la idea de que a este perfil sólo le interesa puestos laborales de corta duración, debido a que este tipo de trabajos interferirán poco en sus actividades escolares o en sus tiempos de ocio, pero serían empleos que generan ingresos que permiten mantener esas actividades. De esta forma, los puestos de trabajo del sector - segmento secundario resultarían más que apropiados a los deseos de esta población joven. El que puedan rotar por diferentes puestos, una vinculación menos formal al propio puesto de trabajo, así como mayor tolerancia a la impuntualidad y al absentismo laboral, iría en la línea de los intereses laborales de los jóvenes en esa etapa vital. Sin embargo, cuando los jóvenes toman la decisión de formar una familia, emanciparse y, con ello, independizarse del hogar familiar de origen, inician la búsqueda de empleos más estables, pero se trata de un camino hacia una vida de mayor estabilidad que dependerá de que existan o no puestos de trabajo que así lo permitan.

Tabla 11.- Aspectos que los jóvenes más valoran de un empleo (\%) por grupos de edad

\begin{tabular}{|c|c|c|c|c|}
\cline { 2 - 5 } \multicolumn{1}{c|}{} & 15 a 19 años & 20 a 24 años & 25 a 29 años & Total \\
\hline Que sea seguro, estable & 77,9 & 80,1 & 85,2 & 81,6 \\
\hline Que proporcione ingresos altos & 15,4 & 14,4 & 9,7 & 12,7 \\
\hline Que tenga prestigio social & 3,3 & 3 & 2,6 & 2,9 \\
\hline Que proporcione mando y poder & 2,3 & 1,5 & 1,3 & 1,6 \\
\hline N.S. & 0,8 & 0,4 & 0,7 & 0,6 \\
\hline N.C. & 0,3 & 0,6 & 0,5 & 0,5 \\
\hline Total & 100 & 100 & 100 & 100 \\
\hline
\end{tabular}

Fuente: Elaboración propia con datos del Sondeo de la Juventud Española - Segunda Oledada - 2009 - Estudio 2822 (CIS) 
Sin embargo, esta última conclusión que deriva en hipótesis no parece cumplirse para el caso de los jóvenes españoles. Es decir, no parece que apuesten (Tabla 11) o valoren los empleos secundarios porque les permitan realizar otras actividades, sino que lo que más valoran de un empleo es la seguridad y la estabilidad en el mismo, independientemente de la edad o grupo de edad de pertenencia. Es decir, los jóvenes apuestan realmente por empleos que encuadraríamos en la definición del sector primario (estabilidad y buenas condiciones) más que por empleos del secundario. Lo que puede haber sucedido, en el marco de una sociedad postmoderna, es un cambio en la valoración social que los jóvenes hacen del trabajo, teniendo un sentido más utilitario que de realización personal.

\section{Conclusiones}

El objetivo de este artículo no era otro que poner en actualidad planteamientos teóricos que se desarrollaron hace décadas. Desde estos clásicos de la Sociología del Trabajo se ha estudiado la vigencia o no, para el caso de los jóvenes españoles, de sus principales postulados. Como hemos podido comprobar, una parte importante de las conclusiones de las perspectivas presentadas se siguen refrendando en la realidad empírica.

Así, en relación con el modelo neoclásico podemos concluir que aún queda validada la hipótesis de presión a la baja en los salarios cuando existe más oferta por parte de los que buscan empleo, que demanda por parte de los empleadores, y esto se materializa aún más en momentos de crisis económica y, con especial incidencia, en el ámbito de los trabajadores jóvenes.

Así mismo, la hipótesis de las diferencias salariales según niveles de formación cualificación que plantea la teoría del capital humano también ha quedado validada en el contexto español analizado. El salario es mucho menor entre aquellas personas que combinan dos características: menor nivel de estudios y más precariedad (tipo de contrato). Además, se ha confirmado para nuestro país que la inversión en capital humano, educación y formación es un factor que ayuda a mejorar la posición de los jóvenes en el mercado de trabajo. Las tasas de paro son menores entre aquellos que tienen estudios superiores que aquellos con nivel formativo menor. Los jóvenes españoles, presentan una alta rotación laboral y, además, hemos podido comprobar cómo la esperanza de vida escolar no ha hecho más que aumentar durante los años de la crisis. En todo caso, para España queda validada también la hipótesis de que una mayor inversión en capital humano aumenta las probabilidades de encontrar empleo o, el menos, de estar en mejor situación en relación con las tasas de paro.

Respecto a las teorías credencialistas se ha visto cómo aparecen barreras que están dificultando la inserción laboral de los jóvenes españoles. Los jóvenes aluden a la falta de experiencia laboral como el principal freno, unido a una inadecuación de la formación a las exigencias del mercado laboral. Así mismo, por su parte, los empresarios españoles ven dificultados sus procesos de selección de personal en sus empresas puesto que ahora no sólo se pide un determinado título sino una serie de competencias que, consideran, no se reciben con los modelos formativos actuales.

En relación con la teoría de la correspondencia, existe esa correspondencia entre el nivel de estudios alcanzado y el puesto laboral ocupado. Niveles altos de estudio, en mayor medida, significan que se ocupe un puesto más elevado en la jerarquía 
ocupacional - mayor estatus ocupacional, pudiendo considerar así al sistema educativo español como un reproductor de clases sociales vinculadas al estatus ocupacional.

En relación con la Teoría del Logro de Estatus se puede concluir, que una parte de los jóvenes españoles describen trayectorias ocupacionales de aproximación sucesiva en la medida en que su estatus ocupacional vendrá determinado por los estatus ocupacionales que hayan conseguido en fases anteriores de su vida laboral. Además, cada vez es más frecuente encontrar vidas laborales y de inserción basadas en la precariedad constante. Y se mantendría una mejoría en el estatus ocupacional de los hijos respecto al nivel de estudios de los padres, pese a que actualmente se comiencen a ver en España procesos de movilidad descendente intergeneracional.

Finalmente, la dualización y/o segmentación del mercado de trabajo español en dos (estables y precarios) es la marca distintiva de éste. En el caso de los jóvenes es el sector secundario de ese mercado el que ocupan (al menos en las primeras fases de su proceso de inserción, y siempre que la trayectoria sea de aproximación sucesiva y no únicamente en precariedad). Los jóvenes, en términos de estructura salarial, son los que tienen un menor salario en comparación con perfiles de mayor edad. Esta dualidad salarial lo es también por tipo de contrato siendo más precaria la situación de los que tienen contratación a tiempo parcial que a tiempo completo. Así mismo, no es del todo cierto que los jóvenes españoles prefieran los trabajos del sector secundario para poder compaginarlos con otras actividades, sino que la inmensa mayoría apuesta por la estabilidad en el empleo (propio del sector primario) con elemento más valorado, siendo así independientemente de la edad.

En todo caso, más allá de lo planteado aquí, aún queda campo de estudio parar comprender mejor los sistemas de relaciones laborales actuales, donde los jóvenes españoles desarrollan sus procesos de inserción laboral y, por medio de estos, sus procesos de inserción social. 


\section{Bibliografía}

Arrow, K. (1973). Higher Education as a filter. Journal of Public Economics, 2, 193-216.

Becker, G.S. (1975). Human Capital. New York: Columbia University Press.

Blau, P. M. y Duncan, D.O. (1967). The American Occupational Structure. Nueva York: Wiley.

Becker, G.S. (1983). Inversiones en capital humano e ingreso. En L. Toharia (Comp.) El mercado de trabajo: Teorías y aplicaciones. Lecturas seleccionadas, (pp. 39-63). Madrid: Alianza Editorial.

Bourdieu, P. (2000). Cuestiones de Sociología. Madrid: Itsmo.

Bowles, S. y Gintis, H. (1976). La meritocracia y el coeficiente de inteligencia. Una nueva falacia del capitalismo. Barcelona: Anagrama.

Bowles, S. y Gintis, H. (1985). La reproducción. Elementos para una teoría del sistema de enseñanza. Madrid: Siglo XXI.

Brunet, I. y Morell, A. (1998). Mercado de trabajo y estrategias de valoración. Revista Española de Investigaciones Sociológicas, 82, 37-71.

Cano, A.B. (2014). Juventud, trabajo y desempleo en los prolegómenos de la crisis económica en España. Reflexiones críticas. Acta Sociológica, 64, 99-120.

Casal, J. (1996). Modos emergentes de transición a la vida adulta en el umbral del siglo XXI: aproximación sucesiva, precariedad y desestructuración. Revista Española de Investigaciones Sociológicas, 75, 295-316.

Casal, J. (1999). Modalidades de transición profesional y precarización del empleo en L. Cachón (Ed), Juventudes, mercados de trabajo y políticas de empleo. (p. 151-180). Valencia: 7 i mig Editores.

Collins, R. (1986). Las teorías funcionalistas y conflictual de la estratificación educativa. Educación y Sociedad, 5, 125-198.

Doeringer, P.B. y Piore, M.J. (1983). El paro y el mercado dual de trabajo. En L. Toharia (Comp.) El mercado de trabajo: Teorías y aplicaciones. Lecturas seleccionadas. (p. 307 -320). Madrid: Alianza Editorial.

García, J.M. y Gutiérrez, R. (1996). Inserción laboral y desigualdad en el mercado de trabajo: cuestiones teóricas. Revista Española de Investigaciones Sociológicas, 75, 269-293.

García, M. A. (1998). Recursos formativos e inserción laboral de los jóvenes. Madrid: CIS - Siglo XXI

García, J.R. (2014). El desempleo juvenil en España. ICE: Revista de Economía, 881, 11-28.

Hernández, T. (1993). El status attainment: a mitad de camino entre teoría y técnica analítica. Revista Española de Investigaciones Sociológicas, 61, 185-198.

Martínez, X. y Marín, A. (2012). Educación y movilidad social en España. En Fundación Encuentro y CECS, Informe España 2012. Una interpretación de su realidad social. (p. 117-172). Madrid: Fundación Encuentro. 
Martínez, R. (2000). Aproximaciones teóricas a los procesos de inserción laboral. Revista del Ministerio de Trabajo y Asuntos Sociales, 26, 65-91.

Martínez, R. (2002). La inserción laboral de los universitarios. Granada: Universidad de Granada y Caja General de Ahorros de Granada.

Merton, R. K. (1980). Teoría y estructura sociales. México: Fondo de Cultura Económica.

Moreno, A. (2015). La empleabilidad de los jóvenes en España. Explicando el elevado desempleo juvenil durante la recesión económica. Revista Internacional de Investigación en Ciencias Sociales, 11 (1), 3-20.

OIEE (2014). Informe OIE sobre jóvenes y mercado laboral. El camino del aula a la empresa. Recuperado de https://oie.es/wp-content/uploads/2015/07/oie_estudio_2017. pdf

Parkin, F. (1984). Marxismo y teoría de las clases. Una crítica burguesa. Madrid: Espasa-Calpe.

Piore, M.J. (1983). Notas para una teoría de la estratificación del mercado de trabajo. En L. Toharia (Comp.) El mercado de trabajo: Teorías y aplicaciones. Lecturas seleccionadas, (p. 193-222).Madrid: Alianza Editorial.

Requena y Ayuso (2016). Teoría sociológica aplicada. Barcelona: Anthropos.

Rothschild, M. y Stiglits, J. (1976). Equilibrium in Competitive Insurance Market: an Essay on the Economics of Imperfect Information.Quarterly Journal Of Economics, 90 (4), 335-374.

Rujas, J. (2015). La Educación Secundaria para Adultos y la FP de Grado Medio ¿Una segunda oportunidad en tiempos de crisis? Revista de la Asociación de Sociología de la Educación (RASE), 8 (1), 28-43.

Sarriés, L. (1999). Sociología Industrial. Las relaciones industriales en la sociedad postmoderna. Zaragoza: Mira Editores.

Spence, M.A. (1973). Job Market Signalling. Quarterly Journal Of Economics. 87, (3), 355-374.

Throw, L. C. (1983). Educación e igualdad económica. Educación y Sociedad. 2, 159-171

Toharia, L. (1983). El mercado de trabajo: Teorías y aplicaciones. Lecturas seleccionadas., Madrid: Alianza.

Trinidad, A., Soriano, R.M. y Barros, F. (2016). La agenda investigadora publicada de los problemas sociales. En A. Trinidad y M. Sánchez (Eds). Marcos de análisis de los problemas sociales. (p. 48-66) Madrid: Catarata.

Vázquez-Fernández, M.J. y Barrera-Algarín, E. (2017). Las prácticas de empresa para la inserción sociolaboral de jóvenes con fracaso escolar. Anduli, 16, 157-174, DOI: http:// dx.doi.org/10.12795/anduli.2017.i16.09. 